\title{
Die Johannesburgse Effektebeurs as rasionele kapitaalmark
}

\author{
Leon M. Brümmer en Pieter J. Jacobs \\ Nagraadse Bestuurskool, Universiteit van Pretoria en Krygstuigkorporasie van Suid-Afrika Beperk
}

\begin{abstract}
The Johannesburg Stock Exchange as an efficient makket. Finality has not yet been reached on the question whether the Johannesburg Stock Exchange complies with the requirements of the efficient market hypothesis. The results of the research that are published in this article is therefore an attempt to make a contribution to the debate regarding the Johannesburg Stock Exchange as an efficient market. By way of serial correlations as well as runs tests an investigation was carried out into the behaviour of the prices of 94 quoted shares for the period 1970 to 1977 . The results of the study give rise to the conclusion that the Johannesburg Stock Exchange does not statistically comply with the weak form of the efficient market hypothesis (the random walk hypothesis), as a measure of dependence between successive price changes was found. Seen from an economic point of view it is, however, doubtful whether investors could use this small degree of dependence between price changes to gain higher returns on share investments.

S. Afr. J. Bus. Mgmt. 1981, 12: 53-59
\end{abstract}

Uitsluitsel met betrekking tot die mate waartoe die Johannesburgse Effektebeurs aan die vereistes vir 'n rasionele mark voldoen, is nog nie verkry nie. Die resultate wat in hierdie artikel voorkom is daarom ' $n$ poging om 'n bydrae in die debat rakende die Johannesburgse Effektebeurs as 'n rasionele mark, te maak. 'n Ondersoek na die markpryse van 94 genoteerde aandele vir die periode $1970-77$ is deur middel van reekskorrelasiekoëffisiënte en die lopietoets uitgevoer. Die resultate van die studie gee aanleiding tot die gevolgtrekking dat die Johannesburgse Effektebeurs nie statisties aan die swak vorm van die rasionele markhipotese (die willekeurige beweging van markpryse) voldoen nie, aangesien 'n mate van afhanklikheid tussen opeenvolgende prysveranderings gevind is. Uit 'n ekonomiese oogpunt gesien is dit egter twyfelagtig of beleggers hierdie afhanklikheid sal kan aanwend om hoër opbrengste op aandelebeleggings te bewerkstellig.

S.-Afr. Tydskr. Bedryfsl. 1981, 12: 53-59

Leon M. Brümmer*

Mede-professor, Nagraadse Bestuurskool, Universiteit van Pretoria,

Pretoria, 0002

Pieter J. Jacob:

Projekbestuurder, Krygstuigkorporasie van Suid-Afrika Beperk

-Aan wie alle korrespondensie gerig moet word

Aanvaar April 1981
Die rasionele markhipotese wat die gedrag van 'n rasionele kapitaalmark beskryf, konstateer dat in 'n vry mededingende kapitaalmark, alle relevante inligting wat aan alle deelnemers in die kapitaalmark bekend is, reeds in die huidige markprys van 'n onderneming se aandele verdiskonteer is en dat markpryse van genoteerde aandele vinnig aanpas in die geval wanneer nuwe inligting bekend gemaak word. In die teorie word drie vorms van die rasionele markhipotese gestel, naamlik die swak vorm (die willekeurige beweging van markpryshipotese), die semisterk vorm en die sterk vorm. Alleenlik die swak vorm is vir die doeleindes van hierdie artikel van belang.

Die swak vorm (die willekeurige beweging van markpryshipotese) konstateer dat opeenvolgende prysveranderings van aandele onafhanklik van mekaar plaasvind en die prysveranderings volgens 'n waarskynlikheidsverdeling plaasvind. Volgens hierdie hipotese kan verwag word dat die waarde van 'n verandering in die markprys van ' $n$ aandeel in periode $t$ onafhanklik van die volgorde van prysveranderings in enige voorafgaande periode is. Kennis van die prysveranderings wat periode $t$ voorafgaan, kan daarom nie gebruik word om die prysverandering gedurende periode $t$ te voorspel nie.

Om 'n kapitaalmark as 'n rasionele mark te toets, moet die afhanklikheid wat daar tussen opeenvolgende prysveranderings bestaan eerstens bepaal word. Indien daar 'n verwantskap tussen 'n prysverandering $P$, en die opeenvolgende prysverandering $\boldsymbol{P}_{i+1}$ bestaan, sal daar 'n statisties beduidende reekskorrelasiekoëffisiënt verkry word wat die verwantskap sal bevestig. In die geval waar die verwantskap 'n reglynige verband aantoon, sal die koëffisiënt se waarde na +1 of -1 neig. Tweedens kan 'n effektemark as rasionele mark getoets word deur die toepassing van die lopietoets. Die lopietoets maak gebruik van die aantal lopies wat waargeneem word en 'n lopie bestaan uit opeenvolgende prysveranderings van dieselfde teken en kan daarom positief wees vir pryse wat kontinu styg, negatief vir pryse wat kontinu daal of nul waar geen prysveranderings plaasvind nie. Wanneer die aantal waargenome lopies met die verwagte aantal lopies - indien die beweging van die markprys van aandele op 'n willekeurige basis verander - vergelyk sou word, kan 'n afleiding met betrekking tot die rasionaliteit van die mark gemaak word. Indien die aantal waargenome lopies minder is as wat teoreties vir ' $n$ willekeurige proses verwag kan word, is dit ' $n$ aanduiding dat daar 'n neiging tot 
tendense te bespeur is. In dié geval sal daar daarom 'n mate van afhanklikheid tussen opeenvolgende markpryse gevind word.

\section{Die Johannesburgse Effektebeurs}

Die omvattendste navorsing ten opsigte van rasionele kapitaalmarke is in die Verenigde State van Amerika met Amerikaanse data uitgevoer. Daar is bevind dat vir alle differensieerbare periodes, van daagliks tot maandeliks, die reekskorrelasiekoëffisiënt klein is en statisties onbeduidend van nul verskil. Solnik' som die gevolgtrekkings van navorsers soos volg op: 'It is now widely believed that the New York Stock Exchange is an efficient market and that U.S. security price behaviour is quite consistent with a random walk concept.'

Ten opsigte van die Europese kapitaalmarkte het Solnik' bevind dat: 'Deviations from the random walk seem slightly more apparent in the European stock price behavior than in the American price behavior. However, the serial correlation coefficients are still quite small ( $R$ square of less than $4 \%$ ) and probably negligible from an investor point of view.'

Hadassin ${ }^{3}$ het die gedrag van 30 aandelepryse wat op die Johannesburgse Effektebeurs genoteer word, ondersoek deur waardes vir die Von Neumann-verhoudingsreekskorrelasie en die lopietoets vas te stel. Alleenlik groot ondernemings met 'n verdiensterekord van minstens 20 jaar en wat vanaf Januarie 1971 tot Desember 1973 op die Johannesburgse Effektebeurs genoteer was, is oorweeg. Die resultate van die ondersoek toon aan dat aandele wat aan die vereistes van die willekeurige beweging van markpryshipotese voldoen, die uitsondering is. Gilbertson en Roux ${ }^{4}$ het die Johannesburgse Effektebeurs ondersoek deur van meganiese handelsreëls en die resultate van groeifondse gebruik te maak. Die resultate van die studie lei Gilbertson en Roux ${ }^{5}$ om die volgende gevolgtrekking te maak: ' . . neither trading rules nor (risk-adjusted) mutual fund managers were able to outperform the market. These findings are in agreement with the results of similar studies on the American stock markets, and are consistent with the EMH. Of course, "consistent with" does not constitute proof of hypothesis validity. However, taking all the evidence together, we must conclude that there is persuasive support for the view that the JSE is an efficient capital market.'

Strebel $^{6}$ kan nie aanvaar dat die Johannesburgse Effektebeurs as rasioneel beskryf kan word nie. Volgens hom sal aandelepryse deur vraag en aanbod beïnvloed word indien die aantal eenhede van 'n aandeel wat per jaar verhandel word, onder 250000 is. By implikasie beteken die stelling dat die markpryse van ongeveer die helfte van die aandele wat op dié effektebeurs genoteer word, nie as rasioneel beskryf kan word nie. Gilbertson en Roux ${ }^{7}$ verwerp dié waarneming. Hulle voer aan dat die volumes wat per aandeel per jaar in Amerika verhandel word, veel hoër is as op die Johannesburgse Effektebeurs en tog word dieselfde waarnemings daar in ondersoeke verkry. Strebel ${ }^{8}$ se verweer is dat aandele met lae volumes, onvoiledige tydreekse ten opsigte van opbrengste het. Om dié rede is dit dan volgens hom nie ver- basend as ondersoeke op geselekteerde aandele aantoon dat die mark rasioneel is nie.

Uitsluitsel met betrekking tot die mate wat die Johannesburgse Effektebeurs aan die vereistes vir 'n rasionele mark voldoen, is nog nie verkry nie. Die resultate wat in hierdie artikel voorkom is daarom 'n poging om 'n bydrae in die debat rakende die Johannesburgse Effektebeurs as 'n rasionele mark te maak.

\section{Metodiek van die ondersoek}

\section{Die data}

Alhoewel daar gepoog is om soveel aandele as moontlik by die ondersoek te betrek, is daar faktore wat die aantal aandele wat vir die studie geskik is, tot 94 beperk.

Daar is van die databank van die Buro vir Finansiële Analise van die Universiteit van Pretoria as die bron van inligting gebruik gemaak. Die inligting met betrekking tot die groepe Myne, Myn-finansieël, Banke en Trustmaatskappye is nog nie in die databank ingevoer nie en was gevolglik nie vir die ondersoek beskikbaar nie. Die keuse van aandele is daarom uit die industriële aandele saamgestel.

Sekere data ontbreek om verskillende redes in die databank. In die eerste plek is daar aandele wat nie vir die volle tydperk, wat van Januarie 1970 tot Desember 1977 strek, op gemelde effektebeurs genoteer is nie. Aandele wat nie vir die volle agt jaar genoteer is nie, is nie oorweeg nie. Tweedens kom gevalle voor waar aandele op een of ander stadium gedurende die tydperk van waarneming vir ' $n$ periode opgeskort is.

Die aandelepryse van die databank word op 'n maandelikse basis weergegee. Hierdie data is oorspronklik uit die maandelikse bulletin van die Johannesburgse Effektebeurs verkry. Die gemiddelde markprys van individuele aandele is op 'n maandelikse basis bereken deur die totale waarde van die aandele wat in 'n spesifieke maand verhandel is, te deel deur die aantal aandele wat in dieselfde maand verhandel is. Die data is vir enige onderverdeling van aandele, omgekeerde onderverdeling, regte uitgifte en kapitalisasie-uitgifte aangepas.

\section{Die reekskorrelasiekoëffisiënttoets}

Die reekskorrelasiekoëffisiënt $(r)$ is 'n maatstaf van die verwantskap wat daar tussen die waarde van ' $n$ veranderlike in periode $t$ en die waarde van die veranderlike $i$-periodes vroeër bestaan. Die waarde van die reekskorrelasiekoëffisiënt is volgens die volgende formule bereken:

$$
r_{s}=\frac{N \sum_{t=1}^{N} \Delta P_{t} P_{t+i}-\left(\sum_{t=1}^{N} \Delta P_{t}\right)\left(\sum_{t=1}^{N} \Delta P_{t+i}\right)}{\sqrt{N \sum_{t=1}^{N} \Delta P_{t}^{2}-\left(\sum_{t=1}^{N} \Delta P_{t}\right)^{2}} \sqrt{N \sum_{t=1}^{N} \Delta P_{t+i}^{2}-\left(\sum_{t=1}^{N} \Delta P_{t+i}\right)^{2}}}
$$

waar:

$r_{s} \quad=$ reekskorrelasiekoëffisiënt van 'n aandeel,

$N \quad=$ aantal waarnemings,

$\Delta \boldsymbol{P}_{t}=$ verandering van die markprys tydens die periode $t$ en $t-1$,

$\Delta \boldsymbol{P}_{t+i}=$ verandering van die markprys tydens die periode $t$ en $t-1, i$-periodes later, 
$t \quad=$ periode (maande), en

$i \quad=$ periode van naloop (maande).

Die finale stap om die beduidenheid van die reekskorrelasiekoëffisiënt te toets, bestaan daaruit dat 'n bepaling van die aantal waarnemings wat buite die vyf persent en een persent limiete van sekerheid val, gemaak word. Die verskillende waarskynlikheidsverdelings word aan 'n nulhipotese getoets wat konstateer dat die reekskorrelasiekoëffisiënte gelyk aan nul is. Die hipotese is op 'n beduidende syfer van 0,05 en 0,01 getoets met die volgende kriterium vir ' $n$ beduidende syfer van 0,05 :

Wys die nulhipotese van 'n nul-reekskorrelasiekoëffisiënt af indien

$$
r<\frac{-1,960}{\sqrt{n-1}} G \text { of } r>\frac{+1,960}{\sqrt{n-1}} G
$$

aanvaar die hipotese of behou reg van uitspraak voor indien

$\frac{-1,960}{\sqrt{n-1}} \leqq r \leqq \frac{1,960_{G}}{\sqrt{n-1}}$

waar:

$\sigma_{G}=$ standaardfout vir die monster, en

$n=$ grootte van die monster .

\section{Die lopietoets}

Die gemiddelde $(\mu)$ van die teoretiese monsterverdeling van die totale aantal lopies volgens 'n willekeurige patroon, kan soos volg bereken word:

$\mu=\frac{2 n_{1} n_{2}}{n_{1}+n_{2}}+1$

waar:

$n_{1}=$ aantal lopies met opeenvolgende positiewe prysveranderings,

$n_{2}=$ aantal lopies met opeenvolgende negatiewe prysveranderings, en

$\mu=$ gemiddeld van teoretiese monsterverdeling van die totale aantal lopies.

Die standaardafwyking $\left(\sigma_{\psi}\right)$ van die monsterverdeling kan nou soos volg bereken word:

$o_{u}=\sqrt{\frac{2 n_{1} n_{2}\left(2 n_{1} n_{2}-n_{1}-n_{2}\right)}{\left(n_{1}+n_{2}\right)^{2}\left(n_{1}+n_{2}-1\right)}}$

waar:

$\sigma_{u}=$ standaardafwyking van die monsterverdeling, en

$u$ = aantal lopies waargeneem.

Die nulhipotese, naamlik dat die monster willekeurig is, kan volgens die volgende kriterium getoets word:

Wys die nulhipotese af indien $Z>1,96$ of $Z<-1,96$; aanvaar die nulhipotese of behou die reg van uitspraak voor indien $-1,96 \leqq Z \leqq 1,96$. Die $Z$-waarde vir 'n beduidende syfer van 0,05 word soos volg bereken:

$$
Z=\frac{u-\mu}{\sigma_{u}}
$$

Volgens die willekeurige beweging van markpryshipotese en vir groot monsters, kan aanvaar word dat die verdeling van die totale aantal lopies van alle tekens volgens die Gauss-verdeling sal wees. Die gemiddeld vir hierdie verdeling sal dan soos volg bereken kan word:

$\left.m=\frac{\left\{N(N+1)-\sum_{i=1}^{3} n^{2}\right.}{N}\right\}$

Die standaardfout kan soos volg bereken word:

$0=\left(\frac{\sum_{i=1}^{3} n_{i}^{2}\left\{\sum_{i=1}^{3} n_{i}^{2}+N(N+1)\right\}-2 N \sum_{i=1}^{3} n_{i}^{3}-N^{3}}{N^{2}(N-1)}\right)^{\frac{1}{2}}$

waar:

$m=$ gemiddeld van Gauss-verdeling,

$\sigma$ = standaardfout van verdeling,

$N=$ totale aantal prysveranderings $(\Delta P)$ in tydreeks, en

$n_{i}=$ aantal prysveranderings van teken $i(i=+,-, 0)$.

\section{Resultate}

Met die status van ondersoeke wat reeds in hierdie verband en met betrekking tot die Johannesburgse Effektebeurs gedoen is, kan die resultate wat tydens hierdie ondersoek verkry is, nou nagegaan word.

\section{Reekskorrelasiekoëffisiënttoets}

Tabel 1 is 'n opsomming van die kumulatiewe persentasie van waarnemings vir reekskorrelasiekoëffisiënte wat kleiner as die limiet van die indelings is. Die volgende waarnemings kan uit die data van Tabel 1 gemaak word:

- Die reekskorrelasiekoëffisiënte wat op 'n maandelikse basis bereken is, is baie klein. Die meerderheid reekskorrelasiekoëffisiënte se waardes kan tussen $-0,3$ en $+0,3$ gevind word. Alleenlik 11 waarnemings is buite hierdie limiete gedoen waarvan nege waarnemings kleiner as $-0,3$ en twee groter as $+0,3$ is. Die resultate word uit 468 waarnemings verkry wat in totaal vir die vyf reekskorrelasiekoëffisiënttoetse gedoen is. Die aantal waarnemings buite gemelde limiete verteenwoordig $2,35 \%$ van die totale aantal waarnemings. Die waarnemings wat buite die limiete van $-0,3$ en $+0,3$ is, is hoofsaaklik uit die eerste reekskorrelasiekoëffisiënttoets $(i=1)$ afkomstig. Daar is in hierdie enkele toets 10 waarnemings buite gemelde limiete gemaak. Agt waardes is kleiner as $-0,3$ en twee groter as $+0,3$.

- Die mediaan van die reekskorrelasiekoëffisiënte is binne die wye limiete van $-0,1$ en $+0,1$ en baie naby aan nul. Die enigste uitsondering is die eerste reekskorrelasiekoëffisiënttoets $(i=1)$. In hierdie geval is die mediaan ongeveer $+0,1$. Daar kan gevolglik afgelei word dat ewe veel positiewe en negatiewe reekskorrelasiekoëffisiënte in 'n tydreeks voorkom. 
Tabel 1 Kumulatiewe persentasie van waarnemings vir reekskorrelasiekoëffisiënte kleiner as die limiet van die indeling vir 94 geselekteerde aandele genoteer op die Johannesburgse Effektebeurs, $1970-77$

\begin{tabular}{|c|c|c|c|c|c|c|c|c|c|c|c|c|}
\hline \multirow{2}{*}{$\begin{array}{c}\text { Naloop- } \\
\text { periode } \\
\text { (i) }\end{array}$} & \multirow{2}{*}{$\begin{array}{l}\text { Korrela- } \\
\text { siekoëf- } \\
\text { fisiënt }\end{array}$} & \multicolumn{11}{|c|}{ Kumulatiewe persentasie } \\
\hline & & $<-0,5$ & $<-0,4$ & $<-0,3$ & $<-0,2$ & $<-0,1$ & $<0$ & $<+0,1$ & $<+0,2$ & $<+0,3$ & $<+0,4$ & $<+0,5$ \\
\hline 1 & $r_{\Delta 1 . \Delta 2}$ & 1,06 & 1,06 & 6.38 & 12,76 & 18,08 & 26,59 & 51,06 & 73,40 & 94,68 & 97,87 & 100,00 \\
\hline 2 & $r_{\Delta 1 . \Delta 3}$ & 0 & 0 & 0 & 3,22 & 28,72 & 56,38 & 88,29 & 98,93 & 100,00 & 0 & 0 \\
\hline 3 & $r_{\Delta 1 . \Delta 4}$ & 0 & 0 & 0 & 5,31 & 27,65 & 59,57 & 84,04 & 96,80 & 97,87 & 100,00 & 0 \\
\hline 4 & $r_{\Delta 1 . \Delta 5}$ & 0 & 0 & 1,06 & 3,19 & 13,82 & 44,68 & 70,21 & 93,61 & 98,93 & 100,00 & 0 \\
\hline 5 & $r_{\Delta 1 . \Delta 6}$ & 0 & 0 & 0 & 9,78 & 29,34 & 57,60 & 85,86 & 96,73 & 100,00 & 0 & 0 \\
\hline
\end{tabular}

Tabel 2 Kumulatiewe frekwensie van waarnemings vir reekskorrelasiekoëffisiënte kleiner as die limiet van die indeling vir 94 geselekteerde aandele genoteer op die Johannesburgse Effektebeurs, 1970-77

\begin{tabular}{|c|c|c|c|c|c|c|c|c|c|c|c|c|}
\hline \multirow{2}{*}{$\begin{array}{l}\text { Naloop- } \\
\text { periode } \\
(\text { l })\end{array}$} & \multirow{2}{*}{$\begin{array}{l}\text { Korrela- } \\
\text { siekoëf- } \\
\text { fisiënt }\end{array}$} & \multicolumn{11}{|c|}{ Kumulatiewe frekwensie } \\
\hline & & $<-0,5$ & $<-0,4$ & $<-0,3$ & $<-0,2$ & $<-0,1$ & $<0$ & $<+0,1$ & $<+0,2$ & $<+0,3$ & $<+0,4$ & $<+0,5$ \\
\hline 1 & $r_{\Delta 1 . \Delta 2}$ & 1 & 1 & 6 & 12 & 17 & 25 & 48 & 69 & 89 & 92 & 94 \\
\hline 2 & $r_{\Delta 1 . \Delta 3}$ & 0 & $\mathbf{0}$ & 0 & 3 & 27 & 53 & 83 & 93 & 94 & 0 & 0 \\
\hline 3 & $r_{\Delta 1 . \Delta 4}$ & 0 & $\mathbf{0}$ & 0 & 5 & 26 & 56 & 79 & 91 & 92 & 94 & $\mathbf{0}$ \\
\hline 4 & $r_{\Delta 1 . \Delta S}$ & 0 & 0 & 0 & 3 & 13 & 42 & 66 & 88 & 93 & 94 & 0 \\
\hline 5 & $r_{\Delta 1 . \Delta 6}$ & 0 & $\mathbf{0}$ & 0 & 9 & 27 & 53 & 79 & 89 & 92 & 0 & 0 \\
\hline
\end{tabular}

Die kumulatiewe frekwensies van waarnemings word in Tabel 2 aangetoon.

Tabel 3 toon die aantal waarnemings vir reekskorrelasiekoëffisiënte buite die limiete vir 'n vyf persent beduidende syfer.

Die volgende waarnemings kan nou uit die data van Tabel 3 gemaak word:

- Die aantal waarnemings wat betekenisvolle reekskorrelasiekoëffisiënte op ' $n$ vyf persent beduidende syfer vertoon, is baie laag. Die grootste persentasie betekenisvolle reekskorrelasiekoëffisiënte is in die eerste toets $(i=1)$ waargeneem. 'n Totaal van $35,10 \%$ van alle waarnemings vertoon hier 'n betekenisvolle reekskorrelasiekoëffisiënt. Vir waardes van $i$ groter as een, neem die persentasie betekenisvolle waarnemings sterk af.

- Daar is geen tendens wat gevolg word namate die waarde van $i$ groter word nie.

Tabel 3 Persentasie van waarnemings vir reekskorrelasiekoeffisiente buite die vyf persent bedui. dende limiete vir 94 geselekteerde aandele genoteer op die Johannesburgse Effektebeurs, $1970-$ 77

\begin{tabular}{cccc}
\hline$i$ & $\begin{array}{c}\% \\
\%\end{array}$ & $\begin{array}{c}\% \\
\text { Totaal }\end{array}$ \\
\hline 1 & 12,76 & 22,34 & 35,10 \\
2 & 4,25 & 3,19 & 7,44 \\
3 & 5,31 & 3,19 & 8,50 \\
4 & 3,19 & 6,38 & 9,57 \\
5 & 7,44 & 3,19 & 13,82 \\
6 & 0 & 4,25 & 4,25 \\
7 & 1,06 & 6,38 & 7,44 \\
\hline
\end{tabular}

- Die persentasie betekenisvolle waarnemings van reekskorrelasiekoëffisiënte volgens 'n een persent beduidende syfer is in alle gevalle aansienlik laer as in die geval van ' $n$ vyf persent beduidende syfer.

Tabel 4 toon die resultate vir waarnemings vir reekskorrelasiekoëffisiënte buite die limiete vir 'n een persent beduidende syfer wat vir verskillende waardes van $i$ verkry is.

Tabol 4 Persentasie van waarnemings vir reekskorrelasiekoeffisiënte buite die een persent beduidende limiete vir 94 geselekteerde aandele genoteer op die Johannesburgse Effektebeurs, 1970 77

\begin{tabular}{cccc}
\hline$i$ & $\begin{array}{c}\% \\
\%\end{array}$ & $\begin{array}{c}\% \\
\text { Totaal }\end{array}$ \\
\hline 1 & $9,580_{G}$ & $+2,58 \sigma_{G}$ & 18,08 \\
2 & 1,06 & 8,51 & 1,06 \\
3 & 0 & 0 & 0 \\
4 & 1,06 & 0 & 5,31 \\
5 & 2,12 & 4,25 & 2,12 \\
6 & 0 & 0 & 2,12 \\
7 & 0 & 2,12 & 2,12 \\
\hline
\end{tabular}

Gilbertson en Roux' het 'n reekskorrelasiekoëffisiënttoets op verskillende aandele gedoen deur die prysverskille oor periodes van een tot 50 dae te gebruik. As die data vir 25 en 22 dae van Gilbertson en Roux se studie vergelyk word met die resultate wat in hierdie studie verkry is, kan dit gestel word dat daar 'n groot ooreenkoms in die data is. Die reekskorrelasiekoëffisiënt is oor die algemeen klein en daar is 'n klein minderheidsgroep van aandele wat koëffisiënte buite die limiete vir twee standaardafwykings toon. 


\section{Lopietoets}

Volgens die nulhipotese moet die willekeurige beweging van markpryshipotese verwerp word indien die waarde $\operatorname{van} Z>1,96$ en $Z<-1,96$ is. Die willekeurige beweging van markpryshipotese kan of aanvaar of uitspraak kan voorbehou word indien $-1,96 \leqq Z \leqq 1,96$ is. Hierdie kriterium is geldig vir' $n$ vyf persent beduidende syfer.

Van Tabel 5 kan gesien word dat daar geen waardes van $Z$ bo die 1,96 waarde verkry is nie en ook geen waardes kleiner as 1,94 nie. Die grootste konsentrasie van waardes vir $Z$ is vir $Z=1,95$ verkry. Hierdie resultate ondersteun die willekeurige beweging van markpryshipotese. Daar is geen resultate in hierdie toets verkry wat daarop dui dat die hipotese verwerp moet word nie.

Tabel 5 Verdeling van waarnemings volgens $Z$ waardes bereken vir 94 geselekteerde aandele genoteer op die Johannesburgse Effektebeurs, $1970-77$, binne die vyf persent beduidende limiet

\begin{tabular}{cc}
\hline$Z$ & Frekwensie \\
\hline 1,94 & 10 \\
1,95 & 59 \\
1,96 & 25 \\
\hline
\end{tabular}

Tabel 6 gee 'n aanduiding van die $Z$-waardes se verdeling vir vier verskillende klasse van aandele volgens die gemiddelde aantal aandele wat per jaar verhandel is. Die persentasieverdeling van waarnemings tussen die drie verskillende $Z$-waardes vir elke groep van gemiddelde aantal aandele wat per jaar verhandel word, is in dieselfde orde. Daarvan kan afgelei word dat aandele wat volgens volume verhandelde aandele gegroepeer word, nie verskillend ten opsigte van die geldigheid van die willekeurige beweging van markpryshipotese reageer nie.

Tabel 6 Verdeling van $Z$-waardes volgens die gemiddelde aantal aandele verhandel per jaar vir 94 geselekteerde aandele genoteer op die Johannesburgse Effektebeurs, $1970-77$

\begin{tabular}{|c|c|c|c|c|c|c|c|c|}
\hline \multirow[b]{2}{*}{$\boldsymbol{Z}$} & \multicolumn{2}{|c|}{$\begin{array}{c}0- \\
100000\end{array}$} & \multicolumn{2}{|c|}{$\begin{array}{c}100001- \\
500000\end{array}$} & \multicolumn{2}{|c|}{$\begin{array}{l}500001- \\
1000000\end{array}$} & \multicolumn{2}{|c|}{$\begin{array}{r}1000001- \\
10000000\end{array}$} \\
\hline & $\begin{array}{c}\text { Aantal } \\
\text { waar- } \\
\text { nemings }\end{array}$ & $\%$ & $\begin{array}{c}\text { Aantal } \\
\text { waar- } \\
\text { nemings }\end{array}$ & $\%$ & $\begin{array}{c}\text { Aantal } \\
\text { waar- } \\
\text { nemings }\end{array}$ & $\%$ & $\begin{array}{c}\text { Aantal } \\
\text { waar- } \\
\text { nemings }\end{array}$ & $\%$ \\
\hline 1,94 & 1 & 16,6 & 6 & 10,9 & 2 & 11,7 & 1 & 6,2 \\
\hline 1,95 & 3 & 50,0 & 31 & 56,0 & 12 & 70,0 & 13 & 81,0 \\
\hline 1,96 & 2 & 33,0 & 18 & 32,0 & 3 & 17,0 & 2 & 12,5 \\
\hline
\end{tabular}

Tabel 7 toon die aantal van albei tekens wat teenoor die verwagte aantal lopies vir elke aandeel waargeneem is. Die resultate toon dat by alleenlik drie van die 94 waarnemings, die totale aantal waargenome lopies die verwagte aantal lopies oortref. Hierdie waarneming is versoenbaar met dié wat tydens die reekskorrelasiekoëffisiënttoets, vir $i=1$, verkry is. Hierdie waarnemings gee aanleiding tot die gevolgtrekking dat 'n neiging bestaan vir markpryse van aandele om tendense oor 'n tydperk te vorm. Hierdie gevolgtrekking word deur die resultate van die lopietoets ondersteun deurdat die aantal lopies wat waargeneem is, kleiner is as wat onder dié omstandighede verwag kan word.

Tabel 7 Die totale aantal lopies waargeneem $(R)$ teenoor die verwagte aantal lopies $(m)$ vir 94 geselekteerde aandele genoteer op die Johannesburgse Effektebeurs, $1970-77$

\begin{tabular}{|c|c|c|c|c|}
\hline $\begin{array}{l}\text { Aandeel- } \\
\text { nommer }\end{array}$ & $\begin{array}{l}\text { Totale aantal } \\
\text { lopies waar- } \\
\text { gencem }(R)\end{array}$ & $\begin{array}{c}\text { Verwagte } \\
\text { aantal lopies } \\
(m)\end{array}$ & $n_{0}$ & $\begin{array}{c}\text { Standaardfout } \\
\left(o_{m}\right)\end{array}$ \\
\hline 1 & 50 & 49,29 & 1 & 4,77 \\
\hline 2 & 46 & 52,20 & 4 & 4,66 \\
\hline 3 & 44 & 50,43 & 2 & 4,75 \\
\hline 4 & $42^{*}$ & 55,88 & 11 & 4,36 \\
\hline 5 & $39 *$ & 51,06 & 4 & 4,55 \\
\hline 6 & 42 & 49.46 & 1 & 4.79 \\
\hline 7 & 41 & 51,02 & 3 & 4,67 \\
\hline 8 & $37^{*}$ & 61,61 & 19 & 4,48 \\
\hline 9 & 40 & 49,48 & 1 & 4,79 \\
\hline 10 & $40^{\circ}$ & 50,72 & 4 & 4,51 \\
\hline 11 & $41^{*}$ & 45,51 & 9 & 4,38 \\
\hline 12 & 54 & 53,92 & 6 & 4,61 \\
\hline 13 & 48 & 51,35 & 4 & 4,58 \\
\hline 14 & $44^{*}$ & 55,48 & 8 & 4,56 \\
\hline 15 & $38 * *$ & 52.76 & 5 & 4.60 \\
\hline 16 & 51 & 55,18 & 9 & 4,44 \\
\hline 17 & 46 & 52,24 & 4 & 4,67 \\
\hline 18 & $40^{*}$ & 56,83 & 11 & 4,44 \\
\hline 19 & 46 & 51,16 & 3 & 4,69 \\
\hline 20 & $34 * *$ & 51,16 & 3 & 4,69 \\
\hline 21 & $40^{*}$ & 52,24 & 4 & 4,67 \\
\hline 22 & $40^{*}$ & 55,46 & 9 & 4,47 \\
\hline 23 & $45^{*}$ & 56.55 & 11 & 4,42 \\
\hline 24 & $38^{*}$ & 56,49 & 10 & 4.49 \\
\hline 25 & $42^{*}$ & 54,70 & 7 & 4,58 \\
\hline 26 & $38^{* * *}$ & 53,92 & 6 & 4,61 \\
\hline 27 & $40^{*}$ & 50,01 & 2 & 4,70 \\
\hline 28 & 48 & 50,38 & 2 & 4,74 \\
\hline 29 & $37 * *$ & 53,10 & 5 & 4,64 \\
\hline 30 & $36 * *$ & 51,16 & 3 & 4,69 \\
\hline 31 & 47 & 53,88 & 6 & 4,60 \\
\hline 32 & $37^{* *}$ & 52,07 & 5 & 4.53 \\
\hline 33 & $35 * *$ & 48,24 & 0 & 4.82 \\
\hline 34 & $40^{*}$ & 51,82 & 4 & 4.62 \\
\hline 35 & 42 & 48,45 & 0 & 4,84 \\
\hline 36 & 44 & 51,02 & 3 & 4,67 \\
\hline 37 & 44 & 51,16 & 3 & 4,69 \\
\hline 38 & $37^{*}$ & 57,06 & 11 & 4.47 \\
\hline 39 & $41^{*}$ & 58,97 & 14 & 4,46 \\
\hline 40 & $40^{*}$ & 54,60 & 8 & 4,47 \\
\hline 41 & $38 * *$ & 53,67 & 6 & 4,58 \\
\hline 42 & 53 & 57,40 & 11 & 4,50 \\
\hline 43 & $32 * *$ & 53,58 & 8 & 4.37 \\
\hline 44 & $43^{*}$ & 54,51 & 9 & 4,38 \\
\hline 45 & $39^{*}$ & 51,14 & 6 & 4,33 \\
\hline 46 & $40^{*}$ & 53,08 & 5 & 4,63 \\
\hline 47 & $38^{\circ *}$ & 52,57 & 5 & 4,58 \\
\hline 48 & $40^{*}$ & 55,18 & 9 & 4,44 \\
\hline 49 & $46^{*}$ & 62,17 & 20 & 4,50 \\
\hline
\end{tabular}


Tabel 7 vervolg

\begin{tabular}{|c|c|c|c|c|}
\hline $\begin{array}{l}\text { Aandeel- } \\
\text { nommer }\end{array}$ & $\begin{array}{l}\text { Totale aantal } \\
\text { lopies waar- } \\
\text { geneem }(R)\end{array}$ & $\begin{array}{c}\text { Verwagte } \\
\text { aantal lopies } \\
(m)\end{array}$ & $n_{0}$ & $\begin{array}{l}\text { Standaardfout } \\
\qquad\left(o_{m}\right)\end{array}$ \\
\hline 50 & 46 & 48,49 & 0 & 4,84 \\
\hline 51 & 44 & 52,11 & 4 & 4,65 \\
\hline 52 & $42^{*}$ & 57,80 & 12 & 4,47 \\
\hline 53 & $37 * *$ & 51,82 & 4 & 4,62 \\
\hline 54 & $45^{*}$ & 57,04 & 12 & 4,40 \\
\hline 55 & 45 & 54,38 & 7 & 4,55 \\
\hline 56 & $36 * *$ & 53,67 & 6 & 4,58 \\
\hline 57 & 41 & 49,92 & 4 & 4,43 \\
\hline 58 & 51 & 51,61 & 4 & 4,60 \\
\hline 59 & $42^{*}$ & 53,50 & 6 & 4,56 \\
\hline 60 & $34 * *$ & 49,40 & 1 & 4,78 \\
\hline 61 & $38 * *$ & 54,85 & 8 & 4,50 \\
\hline 62 & $40^{*}$ & 56,20 & 9 & 4,54 \\
\hline 63 & 41 & 48,36 & 0 & 4,83 \\
\hline 64 & $36^{* *}$ & 52,34 & 5 & 4,56 \\
\hline 65 & 40 & 50,30 & 2 & 4,73 \\
\hline 66 & $38^{* *}$ & 56,20 & 9 & 4,54 \\
\hline 67 & $42^{*}$ & 57,12 & 13 & 4,35 \\
\hline 68 & $37 * *$ & 48,72 & 1 & 4,71 \\
\hline 69 & 40 & 48,53 & 2 & 4,55 \\
\hline 70 & 40 & 54,64 & 7 & 4,57 \\
\hline 71 & 47 & 50,43 & 2 & 4,75 \\
\hline 72 & $39 * *$ & 51,33 & 3 & 4,70 \\
\hline 73 & $42^{*}$ & 58,60 & 15 & 4,38 \\
\hline 74 & $39^{*}$ & 53,67 & 6 & 4,58 \\
\hline 75 & $36^{* *}$ & 50,32 & 3 & 4,60 \\
\hline 76 & $41^{*}$ & 52,91 & 5 & 4,62 \\
\hline 77 & $36^{*}$ & 57,80 & 13 & 4,41 \\
\hline 78 & $35^{* *}$ & 52,20 & 4 & 4,66 \\
\hline 79 & $37 * *$ & 50,17 & 2 & 4,72 \\
\hline 80 & $37 *$ & 53,58 & 8 & 4,37 \\
\hline 81 & 43 & 48,36 & 0 & 4,83 \\
\hline 82 & $32 * *$ & 56,78 & 10 & 4,51 \\
\hline 83 & 51 & 51,98 & 4 & 4,64 \\
\hline 84 & 42 & 50,38 & 2 & 4,74 \\
\hline 85 & 45 & 48,24 & 0 & 4,82 \\
\hline 86 & 45 & 52,11 & 4 & 4,65 \\
\hline 87 & 43 & 48,36 & 0 & 4,83 \\
\hline 88 & 41 & so, 17 & 2 & 4,72 \\
\hline 89 & 42 & 48,36 & 0 & 4,83 \\
\hline 90 & 50 & 49,40 & 1 & 4,78 \\
\hline 91 & 46 & 49,29 & 1 & 4,77 \\
\hline 92 & 44 & 52,91 & 5 & 4,62 \\
\hline 93 & $32 * *$ & 51.00 & 5 & 4,42 \\
\hline 94 & $41^{*}$ & 52,91 & 5 & 4,62 \\
\hline
\end{tabular}

*Aandeel buite die twee standaardfout-limiet

**Aandeel buite die twee standaardfout-limiet na aanpassing vir nulprysveranderings.

Gilbertson en Roux ${ }^{10}$ het die metode wat hier en ook deur ander navorsers gevolg is, naamlik om nulprysveranderings as deel van die onmiddellike voorafgaande lopie te beskou, gekritiseer. Die metode word gevolg omdat dit die betrokke statistiek vereenvoudig. Wat die invloed van hierdie metode op die uiteindelike resultate is, is nie ondersoek nie. Wat wel gestel kan word, is dat in die uiterste geval by alleenlik agt gevalle uit 'n moontlike
94, die aantal waargenome lopies die verwagte aantal lopies oortref. Indien hierdie aanname verslap word, kan verwag word dat die aantal lopies wat waargeneem word, sal styg. Die aanpassing sal meebring dat by 'n aansienlike hoeveelheid minder aandele, die aantal waargenome lopies buite die twee standaardfout-limiet sal val. Die basiese gevolgtrekking sal daarom nie verander nie.

Oor die algemeen is die persentasieverskil tussen die waargenome aantal lopies en die aantal verwagte lopies nie baie groot nie, soos in Tabel 7 gesien kan word.

Indien aanvaar word dat ' $n$ aanpassing gemaak moet word vir die invloed van nulprysveranderings, sal die persentasieverskil nog kleiner wees. Hierdie persentasieverskille, soos verkry uit hierdie studie, is groter as wat deur Fama" vir 'n tydperk van 16 dae verkry is. Met die nodige aanpassing sal die persentasieverskille in dieselfde orde wees.

Gilbertson en Roux ${ }^{12}$ het die lopietoets op 24 aandele wat op die Johannesburgse Effektebeurs genoteer word, gedoen. Die ondersoek is gedoen deur die prysveranderings oor vier verskillende periodes, naamlik een, vier, nege en 16 dae te doen. Gilbertson en Roux ${ }^{13}$ kom in hierdie studie tot die gevolgtrekking dat die beweging van markpryse op die Johannesburgse Effektebeurs nie absoluut, dit wil sê statisties, willekeurig is nie.

\section{Opsomming}

Met die resultate wat in hierdie studie verkry is, kan die gevolgtrekking gemaak word dat die Johannesburgse Effektebeurs nie statisties aan die willekeurige beweging van markpryshipotese voldoen nie, aangesien daar wel 'n mate van afhanklikheid by aandele gevind is. Of hierdie mate van afhanklikheid vanuit 'n ekonomiese oogpunt gesien, van betekenis mag wees, is twyfelagtig. Die gevoel is daarom, alhoewel dit nie spesifiek getoets is nie, dat beleggers nie hierdie afhanklikheid wat daar mag bestaan sal kan aanwend om hoër opbrengste van aandele of portefeuljes van aandele te bewerkstellig nie.

\section{Summary}

Finality has not yet been reached on the question whether the Johannesburg Stock Exchange complies with the requirements of the efficient market hypothesis. The results of the research that are published in this article is therefore an attempt to make a contribution to the debate regarding the Johannesburg Stock Exchange as an efficient market.

The study is vested in the observation of the behaviour of 94 common stock securities over a period of eight years from January 1970 to December 1977. The data bank of the Bureau of Financial Analysis of the University of Pretoria was used as the source of information.

The hypothesis to be verified postulates that the Johannesburg Stock Exchange complies with the requirement of an efficient market. The applied technique makes use of the phenomenon that in an efficient market the prices of securities would adapt to new levels on a random basis. To verify the hypothesis the following two tests were carried out:

Firstly the serial correlation coefficient test provides a criterion against which the relationship between a price change in a period $t$ and a price change during any earlier period can be measured. The test is conducted by apply- 
ing successive price changes on a monthly basis. The periods of time lag changes from one to eight months. When a value of nil is observed for the serial correlation coefficient, it would be an indication of the existence of an efficient market.

Secondly to correlate the results of the serial correlation coefficient test, the runs test is applied. When the quantity of runs observed corresponds with the theoretically expected quantity of runs it would be an indication that an efficient market exists.

The results of the study give rise to the conclusion that the Johannesburg Stock Exchange does not statistically comply with the weak form of the efficient market hypothesis (the random walk hypothesis), as a measure of dependence between successive price changes was found. The serial correlation coefficients, calculated or a monthly basis, are small but of such a nature that independence between successive price changes can not be claimed. The majority of serial correlation coefficients can be found within the range $-0,3$ to $+0,3$. The results of the runs test confirms the findings of the serial correlation coefficient test.

In conclusion it can be stated that although a certain amount of dependence between successive price changes of securities quoted on the Johannesburg Stock Exchange, was found, the degree of dependence is marginal and as a result it is unlikely that this degree of dependence would enable investors to increase their yields.

\section{Verwysings}

1. SOLNIK, B.H. 'Note on the Validity of the Random Walk for European Stock Prices', J. of Finance, Desember 1973, p.1158.

2. Loc cit.

3. HADASSIN, I. 'An Investigation into the Behaviour of Earnings and Share Prices of South African Listed Companies', The Investment Analysts Journal (SA). Augustus 1976, pp.13.

4. GILBERTSON, B.P. en ROUX, F.J.P. 'The Johannesburg Stock Exchange as an Efficient Market', The Investment Analysts Journal (SA), April 1975, pp.21.

5. Ibid, p.27.

6. STREBEL, P.J. 'The Limited Efficiency of the Johannesburg Stock Exchange', The Investment Analysts Journal (SA), Augustus 1977, pp.15.

7. GILBERTSON, B.P. en ROUX, F.J.P. 'Some Further Comments on the Johannesburg Stock Exchange as an Efficient Market', The Investment Analysts Journal (SA), April 1978, pp.21.

8. STREBEL, P.J. 'Thin Trading, Market Efficiency Tests and The Johannesburg Stock Exchange: a rejoiner', The Investment Analysts Journal (SA), Augustus 1978, pp.29.

9. GILBERTSON, B.P. en ROUX, F.J.P. 'Some Further Comments on the Johannesburg Stock Exchange as an Efficient Market', op cit, pp.21.

10. Ibid, p.21.

11. FAMA, E.M. 'The Behaviour of Stock-Market Prices'. J. Bus., Januarie 1\%5, pp.34.

12. GILBERTSON, B.P. en ROUX, F.J.P. 'Some Further Comments on the Johannesburg Stock Exchange as an Efficient Market', op cit, pp.21.

13. Loc cit. 